\title{
How do Virtual Teams Collaborate in Online Learning Tasks in a MOOC?
}

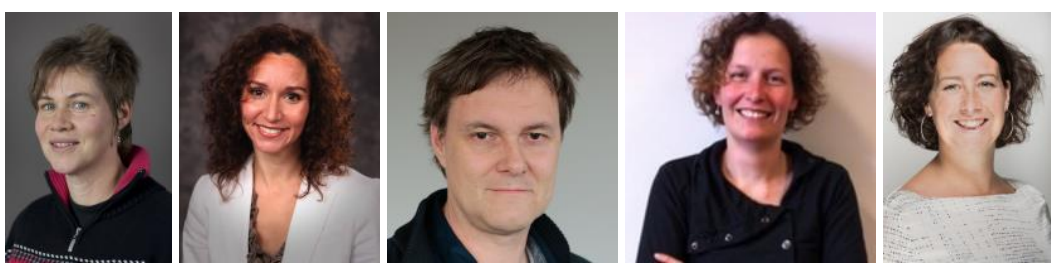

D.M.L. Verstegen 1 , A. Dailey-Hebert ${ }^{2}$, H.T.H. Fonteijn ${ }^{3}$, G. Clarebout ${ }^{4}$, and A. Spruijt ${ }^{5}$

${ }^{1}$ Maastricht University, School of Health Professions Education (SHE), ${ }^{2}$ Park University, USA (Previously at Maastricht University, SBE), ${ }^{3}$ Maastricht University, Department of Work and Social Psychology, ${ }^{4}$ University of Leuven, Center for Instructional Psychology and Technology (Previously at Maastricht University, SHE), ${ }^{5}$ Utrecht University, Faculty of Veterinary Medicine (Previously at Maastricht University, SHE)

\begin{abstract}
Modern learning theories stress the importance of student-centered and self-directed learning. Problem-Based Learning (PBL) supports this by focusing on small group learning centered around authentic problems. PBL, however, usually relies heavily on face-to-face team collaboration and tutor guidance. Yet, when applied in online/blended environments, such elements may not be feasible or even desirable. This study explores how virtual teams collaborate in online learning tasks in the context of a nine-week Massive Open Online Course (MOOC) where international, virtual teams worked on PBL-like tasks. Twenty-one self-formed teams were observed. An inductive thematic analysis resulted in five themes: 1) team formation and team composition, 2) team process (organization and leadership), 3) approach to task work (task division and interaction), 4) use of tools, and 5) external factors (MOOC design and interaction with others). Overall findings revealed that online, virtual teams can collaborate on learning tasks without extensive guidance, but this requires additional communication and technological skills and support. Explicit discussion about group organization and task work, a positive atmosphere, and acceptance of unequal contributions seem to be positive factors. Additional support is required to prepare participants for virtual team work, develop digital literacy, and stimulate more elaborate brainstorming and discussion.
\end{abstract}

Keywords: MOOC, problem-based learning, PBL, open educational resources, online learning, virtual teams, team collaboration, design-based research 


\section{Introduction}

In the context of online learning, the role of the instructor or tutor has consequently been shown to influence student satisfaction, student learning, and persistence (Espasa \& Meneses, 2010; Kauffman, 2015). Yet in recent years, and particularly with the influence of emergent technologies, more selfdirected learning philosophies have emerged (Blaschke, 2012). Problem-Based Learning (PBL) aims at co-construction of knowledge by students (Barrows \& Tamblyn, 1980; Dolmans, de Grave, Wolfhagen, \& van der Vleuten, 2005), but has mainly been used in face-to-face settings and Higher Education curricula.

The first Massive Open Online Courses (MOOCs) specifically aimed at co-construction (Cormier \& Siemens, 2010). However, since then, the majority of MOOCs have had a more traditional course-like set up with a fixed beginning and end point, providing a coherent set of resources and a sequence of activities organized by instructors (Hollands \& Tirthali, 2014). Often, participants work individually, and interaction is limited to discussion fora and peer review of assignments. While MOOCs, in theory, offer a rich environment for self-directed, student-led learning it is not clear to what extent these promises are reached. MOOC research has mostly been quantitative, with limited attention for the experiences of learner populations and instructor-related topics (Veletsianos \& Stepherdson, 2016).

MOOCs are open in the sense that anyone with adequate Internet access can participate in the course, typically without entry requirements and for free. They provide each individual learner with opportunities to engage with the content and the ability to personalize their learning environment (Evans, Baker, \& Dee, 2016). However, there are also important challenges (Fournier \& Kop, 2015). MOOCs are characterized by large dropout, typically more than 90\% (Khalil, Hanan, \& Ebner, 2014). Although this might be partly explained by the fact that participants do not always enter the course with the intention or need to complete it (Clark, 2016), MOOCs have also been criticized for lack of sound instructional design (Toven-Lindsey, Rhoads, \& Berdan Lozano, 2015). The massive scale of MOOCs limits the applicability of proven instructional design principles, for instance because the amount of instructor support, feedback, and guidance is necessarily limited (De Freitas, Morgan, \& Gibson, 2015). Alternative ideas stress learner participation and engagement and connectivism (Ahn, Butler, Alam, \& Webster, 2013; Mackness, Waite, Roberts, \& Lovegrove, 2013), but how to implement this in the design of a MOOC is less clear. MOOC practice shows a widespread use of traditional methodology based on teacher-directed video lessons (Fernández-Diaz, Rodriguez-Hoyos, \& Calvo Salvador, 2017).

The researchers of this study pondered whether adult learners could work collaboratively online and without extensive guidance. This resulted in an exploratory observation study of virtual teams collaborating online on learning tasks in the context of a MOOC about Problem-Based Learning (PBL). PBL focuses on small-group learning centered around authentic problems (Barrows \& Tamblyn, 1980). Traditionally, PBL groups meet face-to-face in the presence of tutor and follow a procedure which includes a collective brainstorm or pre-discussion, followed by individual self-study, and a collective reporting phase or post discussion regarding their findings (Moust, Bouhuijs, \& Schmidt, 2014). Within our study, in the PBL MOOC, teams followed a similar procedure but online and without a tutor.

Both online and tutorless PBL have been used on a small scale, usually with advanced and/or postgraduate students. For example, Barber, King, and Buchanan (2015) used PBL in collaborative, 
online communities to enable students to discuss their own authentic problems. De Jong, SavinBaden, Cunningham, and Verstegen, (2014) found that synchronous forms of online PBL using videoconferencing tools can be successful and similar to face-to-face PBL when students are motivated and prepared. However, van Tilburg (2014) found that this does not hold true for first year full-time students who are accustomed to face-to-face meetings and see no advantage in online PBL. PBL using asynchronous online tools, such as discussion boards or wikis appears to be less successful because this changes the procedure and form of discussion, often resulting in less interaction and superficial discussion (Verstegen et al., 2016a).

With respect to tutorless PBL, Hayashi, Tsunekawa, Inoue, and Fukuzawa (2013) found that students practicing PBL without a tutor were equivalent in final exam scores when compared to those who practiced PBL with a tutor. When exploring tutorless PBL in online environments, Fonteijn (2015) found that learners were able to thrive when afforded more autonomy and ICT support such as mapping software and communication tools. Ertmer and Koehler (2015), on the other hand, found that facilitated online discussions were superior to non-facilitated discussions. Woods, DuncanHewitt, Hall, Eyles, and Hrymark (1996) found that tutorless PBL groups experienced difficulty in workload distribution, building trust, and reliability.

\section{The PBL MOOC}

The MOOC Problem-Based Learning: Principles and design. Students at the centre! was designed to focus on interactive group work, while following PBL principles to enable constructive, contextual, collaborative, and self-directed learning (Dolmans et al., 2005). This MOOC about PBL was designed as a nine-week course with a study load of four to eight hours a week, and the defined target group consisted of people with a professional or personal interest in education in general, and PBL in particular. All assignments were group assignments, which were not graded but peer reviewed by members of other teams. Participants who finished the course received a Certificate of Participation (Verstegen et al., in press).

Within this PBL MOOC, participants completed their personal profile, then formed their own teams using the search facilities of the platform (individuals without a team were assigned to teams after the introduction week; Verstegen et al., in press, 2016b). Since participants were expected to vary widely in background and preferences, the MOOC design intentionally gave teams freedom in deciding how to interact and work together. Their first assignment was to complete a team charter discussing how they intended to collaborate during the MOOC. Subsequently, the teams worked on four authentic problem tasks. They were asked to brainstorm and generate learning questions or issues for further study within their team. Subsequently, they individually searched for and studied relevant sources, some provided in the MOOC and others found elsewhere. Next, teams were asked to collaboratively discuss what they had found in order to answer their own learning questions. The teams worked independently without a tutor. The course facilitators kept a general overview, answered questions on general discussion fora and provided general comments or tips based on their observations of all teams.

This MOOC was implemented in NovoEd (https://novoed.com), a platform that explicitly supports small group work. Each team was given private team space with chat facilities, file exchange, and facilities to schedule meetings (see Figure 1). After a smaller scale pilot test, the first fully open PBL 
MOOC ran from October 5 to December 12 2015. More information about the instructional design and the delivery of the MOOC can be found in Verstegen et al., in press (2016b).

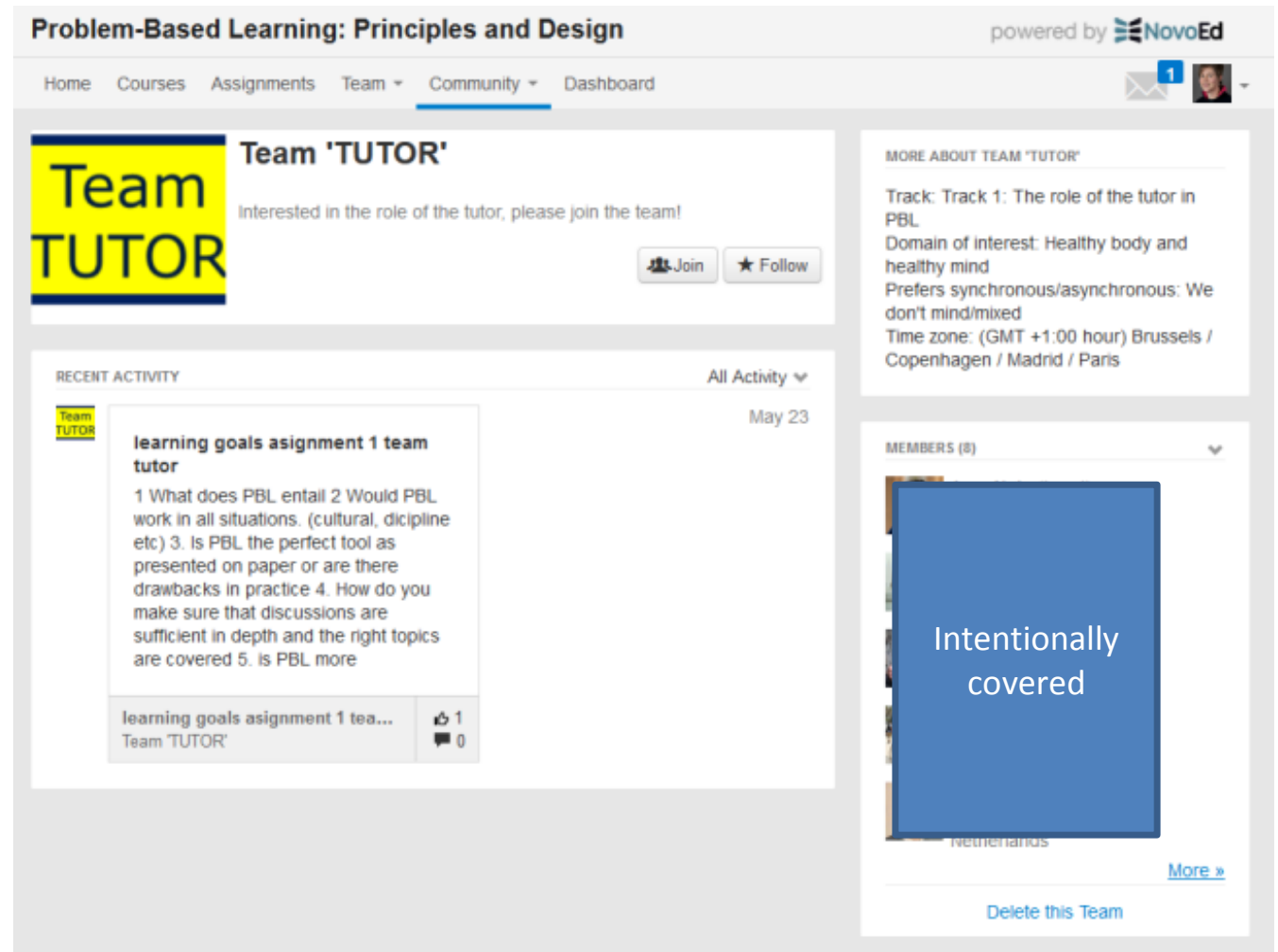

Figure 1. Team space with public profile page and private chat facilities, file exchange and facilities to schedule meetings.

\section{Research Questions}

The design of the previously described PBL MOOC followed a learning format that was in many ways similar to face-to-face PBL, but there were also large differences: there were no tutors, the teams worked online (virtual teams), the team members often did not know each other, teams were largely self-formed, and the participants varied widely in prior knowledge and experience. With this, our research questions for this study were:

- How do online, virtual teams collaborate on PBL tasks without the guidance of a tutor?

- How can we support online, virtual, tutorless teams in a MOOC?

\section{Method}

\section{Participants}

For this study, participants took part in the PBL MOOC described above from October 5 to December 12 2015. The MOOC started with 2989 participants. Just over a quarter (26\%) filled in their profiles 
and became part of a team. Of these 109 teams, 49 (44\%) finished the course and 264 participants received a certificate of participation. The majority of teams was formed by the participants themselves. After the first week, the facilitators formed 13 teams from the remaining participants, but since almost all of these teams were unsuccessful, they were excluded from this study. Questionnaire data show, that participants came from all over the world. Surprisingly, about two thirds of the participants that filled in their profile had never taken part in a MOOC before (Verstegen et al., 2016b).

For this study a subset of 21 teams was selected. The observers (the authors and three research assistants) asked permission to observe the teams' communication and collaboration in their NovoEd team space. Selection of teams was random except that teams that showed no recent activity were excluded. Up to week four, selected teams were replaced if they did not give consent, were no longer active, or if they communicated in a language the observers did not understand.

\section{Procedure}

Observers contacted the team leaders of the selected teams using a standard text message to explain the study. If the team leaders agreed the same message was posted in the team chat, stating explicitly that the observer would immediately stop observing the team if any member had objections. Observers did not participate in any way, but only followed the conversation in the team chat and any other documents or tools that they had access to (e.g. Googledocs files, uploaded documents, and links to other tools used by the team). Every week they collected the teams' assignments and completed an observation form. After the end of the MOOC the observers made short descriptions of the teams. The entire content of the team chat was copied into excel files.

\section{Data}

The data corpus for this study included:

- written team chats in NovoEd team space;

- files that teams uploaded;

- shared working documents linked to the team space;

- submitted assignments;

- weekly forms completed by the observers; and

- descriptions of the observed teams written by the observer.

\section{Analysis}

A priori the researchers of this study did not have defined expectations or ideas about how teams would or should collaborate in this PBL MOOC. Therefore, this study is descriptive and exploratory in nature. The aim was not to find out which teams were 'good virtual teams,' nor to find the best way to be a virtual team. Rather we aimed to discover how virtual teams can communicate and collaborate, and which factors might play a role in their interaction. Based in the constructivist paradigm (Bergman et al., 2012), thematic analysis was used in an inductive way to uncover latent themes (Braun \& Clarke, 2006), guided by the research questions. Following Braun and Clarke's (2006) guidelines, the researchers familiarized themselves with the data by reading the descriptions of the observed teams, 
the weekly observation forms, and the team chats (copied from NovoEd to excel files). Initial codes were generated and potential themes collected.

The research team met twice to review and refine the themes, resulting in the final definition of themes and subthemes/aspects. In order to further refine the themes and find illustrative examples a subset of five team chats was selected for recoding. This selection was purposeful and sought to show a variety of ways that teams communicate and collaborate online. Chats with up to 500 contributions were entirely double coded. For longer chats, 250 contributions were double coded and the remaining contributions single coded. The two coders met to compare and discuss their coding: to reach an agreement about identified themes and subthemes.

\section{Results}

In this section we briefly describe the five resulting themes illustrated with quotes from the five teams that were included in the dataset for recoding.

\section{Team Formation and Team Composition}

Teams in this study were formed by the participants themselves, and team members usually shared a commonality such as country of origin, institution, or interest in the same domain. However, in many cases team members had never met before. Conversation about team composition took place mainly at the beginning when participants introduced themselves, though usually very briefly, with team members mentioning their background and PBL experience and sometimes their motivation to follow the course. Some introductions were a few sentences long, but many were as short as: "Hi everyone, I don't have any PBL experience either." After the first introductions participants rarely mentioned their background or place of work, except occasionally when they were looking for an example, e.g.: "We designed this course five years back in my country... in a medical school where I was working that time." For a more detailed analysis of team charters and first interactions, see Mayer (2016).

Most teams started out quite large, around 10-15 people. In some teams there was explicit discussion about team size, e.g.: "I have 6 more membership requests from other people. Personally I think the 12 team members we have now is the right amount of people to successfully finish the assignments. What do you guys think?" Hagedoorn (2017) analyzed MOOC dropout rates quantitatively and found that dropouts occurred mostly early in the course and could be predicted by early passive behavior such as not filling in the profile questions. Within our study, we observed that all teams shrunk in size and by the halfway point of the MOOC (approximately week four), there seemed to be a reasonably steady core of active participants of around four to six per team. Sometimes, participants explained why they were leaving: "Hi all, I have decided to stop with this MOOC .... I stop now, because I have too less time to do the assignments." Other team members seemed to appreciate such an explicit explanation and reacted with understanding: "...sorry to see you go. All the best in your new job.” Other participants did not explicitly leave, but stopped contributing. This lack of involvement sometimes went unnoticed, but some team leaders actively addressed inactive members and eventually removed them from the team: "Hello, I write to you to seek clarifications regarding the status of your future participation and contributions to the activities on the group. Please let us know since it would help us streamline things better." 
Large dropout caused problems if teams became too small, as we saw in some teams that stopped during the course. There was one exception: one team started with six members, and quickly shrunk to only two active members. However, they knew each other and also met face-to-face, which seemed to enable them to work together efficiently and finish the course regardless:

Hello due to the burden of institutional work, we have had discussions face to face about the role of tutor during the post-discussion phase, based on the guiding questions and the Web resources and now we are analyzing the information to complete the assignment.

Some withdrawing team members asked permission to stay on as a passive team member, and this was generally accepted. In some teams, other team members actively tried to keep people in by proposing to be more flexible in deadlines and work division:

I wonder why members are deciding to quit in hurry. please do not do it...To me some delay is no problem ... everybody will contribute according to his or her convenience and other members will keep the wheel moving till end but each and every member will keep on doing self-study and observing the team activities at their convenience.

\section{Team Process (Organization and Leadership)}

How to organize the team was primarily discussed at the beginning of the MOOC, when the teams completed their team charter. Some teams maintained fixed roles with the same team leader throughout the course, while others explicitly chose to rotate roles. One team specifically appointed someone who had already experienced PBL as team leader for the first task. Spending more time on planning, discussing roles and role division, and discussing the steps to take and the tools to use seemed to have a positive effect on team collaboration. One participant suggested: "I also think the process manager should suggest some 'deadlines' for the assignment, so we can contribute to the assignment on moment that is convenient in our own schedule," while another stated:

We are going to have 2 persons for each role and will changing the role once every two weeks. $\mathrm{XX}$ is taking the role of the summarizer, $\mathrm{YY}$ is taking the role of process manager. $\mathrm{ZZ}$ is taking the role as searcher... Role distribution is part of our PBL self- experiment, so we decided to switch roles on a regular basis so everybody can try out different duties. Since we are not always available, it is nice to have each role covered by 2 people.

After a few weeks the team charters were usually not up-to-date anymore, because not all team members were still active. However, there was little explicit discussion on role division or team leadership then. This seemed to be largely arranged implicitly in the discussion of how to work on specific tasks (see below). Though rare, explicit reflection on team processes did help teams to work together effectively and might also have helped other team members to remain engaged in the course:

$\mathrm{XX}, \mathrm{YY}$, and ZZ, let us know what we can do to keep you on board and in which way we need to reorganize our way of working together. Perhaps we could update the charter or make a new document to reflect the schedule?

One team, kept updating the team charter and someone explicitly pointed out the role division of the coming week: "XX, you are team leader for this week's assignment. Do you have time to coordinate the group and this week's tasks or should I step in for you?” Frequently, there were team members 
apologizing when they had not been able to fully participate for personal or work-related reasons. Overall, team members responded positively to explanations for unequal contributions: "I hope you are ok. We all have troubles from time to time. This is life. The assignment is not with a fixed deadline and we are supposed to continue the discussion during the next week."

Team collaboration seemed to run smoother when teams showed adaptability and actively maintained a positive atmosphere: “... not all of us have English as a first language, so I think we will have to be aware of that.” Negative remarks were very rare. Only one example was found:

$\mathrm{XX}$ the error is that $\mathrm{YY}$ once again submitted his individualistic stuff without consulting or letting us know and I am unable to do anything about it. I guess that means that we have been hit badly this time. We had requested and informed him earlier to refrain from doing the same...

Team collaboration was stimulated by teams acknowledging others' contributions and being proud of the results with statements such as: "Good morning my lovely team. Finally I found the mind map which is brilliant! Thank you it is such a great addition to the assignment," and "It was a great experience working together with you. I'm proud of our team that we finished all the assignments!"

\section{Approach to Task Work (Task Division and Interaction)}

This theme is used to discuss how teams addressed concrete tasks in the PBL MOOC, for example, how they manage time or exchange information: "I just tried to set up a meeting poll with the dates proposed above by... Please double-check and let us know here in the chat (for upcoming meetings that we will have to schedule)," "I started the brainstorm in our document. I am looking forward to read your thoughts and questions on the problem." In some teams, proactive team members regularly pushed information, actively sought contributions, and supported others:

Hello everyone! I was updating our [assignment]. We are missing input from [team member names]. Part A of the assignment is due in six hours, so I will wait four more hours before putting all of our questions together and clustering them. Thank you all!

Early task work interaction focused on content and role clarification, and on mobilizing team members, with comments such as: "I signed up to be a contextualizer, but I don't know what that is!" and "I still don't understand which references I am supposed to summarize: the ones in the assignments or the ones I get from the searchers. What do you think?” After initial task planning, groups developed routines and shared more succinct planning messages at the start of a new assignment: "Duties for next week are 1: I am the process manager and reporter (summary hand in). 2: $\mathrm{XX}$ and $\mathrm{YY}$ are the searcher of this week. 3: Me and ZZ are summarizers." It helped when team members engaged in error correcting and back-up behavior:

Hi everyone, I had a spontaneous day off yesterday and now I see I have missed a lot. I will have few hours today and half a day tomorrow, so if [team member names] need some help with summary just let me know. I will now read our problems and comments to get back to track :).

Most teams did not change set routines and there was limited reflection on past performance, with a few exceptions such as: 
Have you noticed in the videos showing PBL sessions in [anonymized university name], that they have a phase called "CLUSTERING" where they group the topics and questions into more scalable entities? I think it's time for us to do this too.

Only rarely did team members engage in explicit elaboration, reflection, or reaction to information from other team members, encouraging different perspectives or collectively drawing conclusions. Most teams seemed to simply divide the work and patch together what they had found. On the whole, in the team chats evidence of co-construction of knowledge is scarce with only a few exceptions: "Thanks to [team member names] for excellent contributions. I summarized all the texts in a concept map. I hope I have captured and integrated the essence of what you have researched.”

Inspection of the last assignments showed, however, that some teams did manage to engage in coconstruction resulting for innovative and creative products, such as a video clip where team members discussed what they had learned from the course and how they intended to apply it, or a mock design for a training about PBL for colleagues in their own university Verstegen et al. (2016b).

\section{Use of Tools}

The "use of tools" theme was used to categorize comments about the platform's facilities and functionalities and other tools external to the MOOC platform. The results show that many participants were not accustomed to using online learning environments. The observers noticed how the participants' digital literacy impacted their teams, and witnessed a steep learning curve for some in using online tools. Most technological challenges occurred within the first two weeks and included: 1) trouble accessing files or documents, 2) issues with adding or saving their comments to shared files, or 3) challenges when trying to access or evaluate other teams' work. For example:

Thanks XX. I have uploaded doc now on google docs and google drive but I do not know how to bring it here because I failed to upload this doc from here. Thanks if you can help me. Then it will be available for change. Sorry for inconvenience.

While some teams discontinued the MOOC for various reasons (including technological challenges), other teams had a quick response time in providing peer support to resolve technological issues and demonstrated an ability to mentor and coach one another through technical challenges. Throughout the course participants engaged in problem solving, mentoring teammates to overcome technological challenges, and identified tools to benefit their team's communication. However, the observers also saw a team member leaving a team because of inability to master the tools that their team had decided to use.

As participants learned about using the NovoEd platform, they also had to adapt to working in an online environment with geographically dispersed team members (often in various times zones around the world). Teams usually started off with the facilities provided in the platform: chat and file exchange, and the Google tool suite that they could easily link to. Some teams were more adventurous and experimented with alternatives, like padlet walls, mind or concept mapping tools, or tools to make visual representations in infographics: "I've also used Slack, a free, online intranet type tool but I've never set it up myself, do any of you have experience using it?" "I would like to try Lexicographer: identified and collaboratively defines words and phrases; shared definitions." Occasionally, participants were inspired by what they had seen from other teams: 
Good morning! Would you be interested in submitting a mind map this time? I would like to try something different and I think it would be interesting to visualize our results (some of the other teams did great jobs being creative!).

Most teams that tried to organize synchronous discussion sessions, for example in Google Hangouts, gave up on the idea because busy schedules and time zone differences made it impossible to meet:

I don't want to press ahead but I think a week goes by so quickly and it's not so easy for us to work together due to the different time zones. So I prepared an edupad (see the link) with the next steps. It's similar to a google docs: everyone can write and everyone is attributed automatically a different colour. But no problem if we choose another way to collaborate.

Thus, communication remained mainly asynchronous, although some teams tried to find other solutions: "We could copy the questions from the form in a doc and work on it simultaneously/together? As for real-time discussion, I have experience running a weekly twitter chat which facilitates easy discussion using a predetermined hash tag."

\section{External Factors (MOOC Design and Interaction With Others)}

Within this MOOC, interaction with facilitators and participants from other teams was possible on the discussion forum. The facilitators organized weekly Google Hangouts sessions. All assignments (except for the team charter) were public to all participants. Additionally, at the end of each PBL task participants were explicitly asked to peer review the work of three other teams. In their team chats some teams referred to points made in the general discussion forum or sessions by the facilitators: "FYI, here is an interesting list of research questions published by another team here: [link to discussion forum]," and "I noticed the teaching team addresses many practical issues in the weekly google hangout." There is also evidence of collaborating and exchanging information with other teams: "I would suggest maybe a collaboration with another team $(<$ team name $>)$ that are working on language classrooms too."

For some completing peer reviews served as a great example of what was possible. Some teams felt the need to improve their quality of work and also learned from other teams' assignments:

Did you see all the other submissions? [link to assignments]. Some are works of art! I had not realized what it would be like for others to review us. I think that what's most important is what we learned and how we worked, but now that I did the peer reviews I have a better understanding of how we could further improve our assignments for others, should we want to.

A critical comment from one participant was that peer reviewing was time consuming and not always clarifying: "Although some mind maps were impressive, for me their answers became not really clear. One submission I had to review was over 25 pages. The review took me more than an hour."

Participants frequently provided links to resources within the MOOC that they found useful, especially the mini-lectures, and to external resources, such as websites and journal articles. And although the design of the MOOC was innovative and must have been new to most participants, there were only a few comments about this: 
As you will notice the course itself is scaffolding our learning: First what PBL is all about, then Problem design and now course design. The obvious additional parts of the design in addition to problem are Supportive Info, Procedural Info, and Part Task Practice as also taking a course dividing into blocks which run sequentially.

\section{Discussion}

This study has revealed that it is possible for online, virtual teams to collaborate on learning tasks without extensive guidance, but this requires additional communication and technological skills and support. In the MOOC Problem-Based Learning: Principles and design. Students at the centre! most teams worked fully online. Self-composed teams usually shared a common interest or lived in the same area, but often team members did not know each other. It is surprising that the teams did not spend much time on introductions or getting to know each other. Apparently, the MOOC evoked a taskfocused approach, possibly because of the strict timeline required for the completion of assignments.

Within this study, we discovered that virtual teams can develop different ways to successfully communicate and collaborate. Some teams had a strong team leader and fairly fixed roles throughout the course, whereas others rotated roles. We saw the importance of having team members explicitly discuss team process and task division, and set clear expectations and timelines. This is in accordance with Wen, Yang, and Rosé (2015) who studied another NovEd course (with a different instructional design). In our study, teamwork was smoother in teams that remained positive, encouraged others, and set agreed upon patterns for communication. Collaborative creation of the team charters helped with this aspect.

The first weeks showed many changes with team members dropping out and new members dropping in. This is common according to Evans, Baker, and Dee (2016). Some teams chose to revise their team charter after a few weeks to account for a redistributed workload, while others did not. All teams lost members and the majority of teams ended up with an average size of four to six members. Gurtner, Tschan, Semmer, and Nägele (2007) suggest that team reflexivity is rare when teams are under time pressure (due to teams often wanting to perform rather than learn). However, in our study, some teams seemed to have the capacity to reflect upon on-going change. Successful teams showed team adaptability and were able to plan reactively, which helped them deal with unexpected events.

Like Littlejohn, Hood, Miligan, and Mustain (2016) we observed a large diversity in motivation and self-regulated learning skills of MOOC participants. We also found large differences in participants' online skills: for many it was their first MOOC (see Salazar-Márquez, 2017), while some others were actively looking for more advanced tools and new ways to collaborate. This may have been the reason that many teams only used the standard toolset: chat box, file exchange, and google docs. Most teams did not organize synchronous contact moments, presumably due to scheduling challenges. Haines (2014) argues that the development of virtual teams is different and requires explicit attention. De Freitas, Morgan, and Gibson (2015) stress the critical role technology plays in hosting a MOOC, and indeed the virtual teamwork in this study may have been influenced in positive and negative ways by the specific platform that was used. In the team chats we did not see a large amount of co-creation, but rather individual contributions compiled together in one document. A minority of groups engaged in a deeper level of discussion where input was combined and synthesized, with new insights developed 
collaboratively (as intended with the PBL process). This may be partly due to limited digital literacy, as co-creation requires intensive brainstorming and discussion. Basic asynchronous tools such as chat and file exchange do not optimally support intensive interaction.

In conclusion, characteristics of successful collaboration in virtual teams were: 1) consistent communication through multiple channels, 2) adjusted workload based on member needs, 3) ongoing explicit discussion of the workflow and/or a strong leader organizing the group process and task division, 4) acceptance of different abilities and skillsets of members, and 5) stimulation and assistance of team members when needed (i.e. due to technical challenges, language barriers, etc.). Moving forward it will be important to consider these factors in future MOOCs and therefore we offer the following recommendations.

\section{Prepare the Participants for Virtual Teamwork}

Given the wide variety of skills and expertise, it is important to prepare learners for virtual teamwork. Yet, it is also clear that there is not one universal or best solution to address this need. Therefore, we recommend giving several concrete examples of how virtual teams can successfully collaborate and communicate. We recommend that facilitators try to stimulate teams to spend more time on team formation and building trust, for example by discussing their knowledge and experience regarding PBL or digital tools, and how they might be able to complement and help each other. It will also be important to prepare teams for dropout and team changes, particularly during the creation of the team charter. Teams could be explicitly advised to update and revise their team charter after the first weeks.

\section{Stimulate the Teams to Elaborate}

We recommend highlighting the importance of co-creation, deeper discussions, and brainstorming while also suggesting tools that can support the required intensive interaction. Along this line, we recommend encouraging teams to engage in some amount of synchronous contact and to explicitly stimulate participants to ask explanatory and critical questions, visualize (e.g., in concept mapping), and synthesize the discussion. Since we observed the impact of peer evaluations to evoke interest and discussion, we suggest stimulating this more explicitly, for example by creating a "virtual gallery," where all submissions can be reviewed and rated by other teams and MOOC participants.

\section{Develop Digital Literacy}

Given the significant divide between learners' digital skills and their required use of technology to participate in the MOOC, it is important to recognize the steep learning curve for some. We recommend providing additional support to educate participants on technology available in the platform. Furthermore, it is important to acknowledge collaborative tools available outside the platform. We suggest describing more innovative tools and how they could be used during this MOOC, or involving participants in a running list to suggest and rate the effective communication tools they use.

\section{Limitations and Further Research}

This study was descriptive and exploratory in nature. We selected teams that were active throughout the course in order to explore how their collaboration evolved, but this has resulted in a selection bias 
towards successful teams. Future research should look into factors that hinder collaboration in virtual teams or reasons that virtual teams fail at their tasks. The teams that we observe may also have been in contact via other channels that we did not have access to, and so our observation data may be incomplete. Future research could also attempt to replicate this instructional design on another platform and/or with other tools and facilities, for example tools that explicitly stimulate interaction and discussion. Participatory research might enable researchers to fully observe and experience collaboration in virtual teams. Finally, future research could focus on implementing the recommendations above and could study the effects on virtual teams in a next run of the PBL MOOC.

\section{Conclusion}

In the MOOC Problem-Based Learning: Principles and design. Students at the Centre! self-formed teams worked online. This study has revealed that it is possible for virtual teams to collaborate on PBL learning tasks without a tutor, but this requires additional communication and technological skills and support. Explicit discussion about group organization and task work, a positive atmosphere, and acceptance of unequal contributions seem to be positive factors. Additional support is required to prepare participants for virtual team work, develop digital literacy, and stimulate more elaborate brainstorming and discussion. 


\section{References}

Ahn, J., Butler, B. S., Alam, A., \& Webster, S.A. (2013). Learner participation and engagement in open online courses: Insights from the Peer 2 Peer University. MERLOT Journal of Online Learning and Teaching, 9(2). Retrieved from http://jolt.merlot.org/volgno2/ahn 0613.htm

Barber, W., King, S., \& Buchanan, S. (2015). Problem based learning and authentic assessment in digital pedagogy: Embracing the role of collaborative communities. Electronic Journal of eLearning, 13(2), 59-67. Retreived from www.ejel.org

Barrows, H. S., \& Tamblyn, R. M. (1980). Problem-based learning: An approach to medical education. New York, NY: Springer.

Bergman, E., De Feijter, J., Frambach, J., Godefrooij, M., Slootweg, I., Stalmeijer, R., \& Van Der Zwet, J. (2012). AM last page: A guide to research paradigms relevant to medical education. Academic Medicine: Journal of the Association of American Medical Colleges, 87(4), 545. doi:10.1097/ACM.obo13e31824fbc8a

Blaschke, L. M. (2012). Heutagogy and lifelong learning: A review of heutagogical practice and selfdetermined learning. The International Review of Research in Open and Distance Learning, 13(1), 56-71. Retrieved from http://www.irrodl.org/index.php/irrodl/article/view/1076/2087

Braun, V., \& Clarke, V. (2006). Using thematic analysis in psychology. Qualitative Research in Psychology, 3(2), 77-101.. doi: 10.1191/1478088706qpo63oa

Clark, D. (2016). MOOCs: Course completion is wrong measure. Retrieved from http://donaldclarkplanb.blogspot.nl/2016/02/moocs-course-completion-is-wrongmeasure.html

Cormier, D., \& Siemens, G. (2010). Through the open door: Open courses as research, learning, and engagement. EDUCAUSE Review, 45(4), 30-39. Retrieved from http://www.educause.edu/ero/article/through-open-door-open-courses-research-learningand-engagement

De Freitas, S. I., Morgan, J., \& Gibson, D. (2015). Will MOOCs transform learning and teaching in higher education? Engagement and course retention in online learning provision. British Journal of Educational Technology, 46(3), 455-471. doi:10.1111/bjet.12268

Dolmans, D. H. J. M., de Grave, W., Wolfhagen, I. H. A. P., \& van der Vleuten, C. P. M. (2005). Problem-based learning: Future challenges for educational practice and research. Medical Education, 39, 732-41. doi:10.1111/j.1365-2929.2005.02205.x

De Jong, N., Savin-Baden, M., Cunningham, A. M., \& Verstegen, D. M. L. (2014). Blended learning in health education: Three case-studies. Perspectives on Medical Education, 3, 278-288. doi: 10.1007/s40037-014-0108-1 
Espasa, A., \& Meneses, J. (2010). Analyzing feedback processes in an online teaching and learning environment: An exploratory study. Higher Education, 59(3), 277-292. doi: 10.1007/s107340o9-9247-4

Evans, B. J., Baker, R. B., \& Dee, T. S. (2016). Persistence patterns in massive open online courses (MOOCs). Journal of Higher Education, 87, 206-242. doi.org/10.1080/00221546.2016.11777400

Ertmer, P. A., \& Koehler, A. A. (2015). Facilitated versus non-facilitated online case discussions: Comparing differences in problem space coverage. Journal of Computing in Higher Education, 27, 69-93. Retrieved from https://www.learntechlib.org/p/161629/

Fernández-Diaz, E., Rodriguez-Hoyos, C., \& Calvo Salvador, A. (2017). The pedagogic architecture of MOOC: A research project on educational courses in Spanish. The International Review of Research in Open and Distributed Learning, 18(6). Retrieved from http://www.irrodl.org/index.php/irrodl/article/view/2964/4374

Fonteijn, H. (2015). Making students responsible for their learning-Empowering learners to build shared mental models. In A. Dailey-Hebert \& K. S. Dennis (Eds.), Transformative perspectives and processes in higher education (pp. 97-116). Springer International Publishing.

Fournier, H., \& Kop, R. (2015). MOOC learning experience design: Issues and challenges. International Journal on E-Learning, 14(3), 289-304. Waynesville, NC USA: Association for the Advancement of Computing in Education (AACE). Retrieved from https://www.learntechlib.org/primary/p/150661/

Gurtner, A., Tschan, F., Semmer, N, \& Nägele, C. (2007). Getting groups to develop good strategies: Effects of reflexivity interventions on team process, team performance, and shared mental models. Organizational Behavior and Human Decision Processes, 102, 127-142.doi: 10.1016/j.obhdp.2006.05.002

Hagedoorn, T. R. (2017). Massive open online courses profiling for dropout prediction. (Unpublished bachelor thesis). Maastricht University, The Netherlands.

Haines, R. (2014). Group development in virtual teams. Computers in Human Behavior, 39 (C), 213222. doi.org/10.1016/j.chb.2014.07.019

Hayashi, S., Tsunekawa, K., Inoue, C., \& Fukuzawa, Y. (2013). Comparison of tutored group with tutorless group in problem-based mixed learning sessions: A randomized cross-matched study. BMC Medical Education, 13(1), 158. doi: org/10.1186/1472-6920-13-158

Hollands, F. M, \& Tirthali, D. (2014). MOOCs: Expectations and reality. Full report. New York, NY: Columbia University, Teachers College, Center for Benefit-Cost Studies of Education.

Kauffman, H. (2015). A review of predictive factors of student success in and satisfaction with online learning. Research in Learning Technology, 23(1), 1-13.

http://dx.doi.org/10.3402/rlt.v23.26507 
Khalil, H., \& Ebner, M. (2014). Moocs completion rates and possible methods to improve retention: A literature review. In Proceedings of EdMedia, World Conference on Educational Media and Technology (Vol. 2014, pp. 1305-1313). Waynesville, NC: Association for the Advancement of Computing in Education (AACE).

Littlejohn, A., Hooda, N., Milligan, C., \& Mustain, P. (2016). Learning in MOOCs: Motivations and self-regulated learning in MOOCs. Internet and Higher Education, 29, 40-48.

doi.org/10.1016/j.iheduc.2015.12.003

Mackness, J., Waite, M., Roberts, G., \& Lovegrove, E. (2013). Learning in small, task-oriented connectivist MOOC: Pedagogical issues and implications for higher education. The International Review of Research in Open and Distance Learning, 14(4). Retrieved from http://www.irrodl.org/index.php/irrodl/article/view/1548/2636

Mayer, L. (2016). What can we learn from virtual team collaboration in a cMOOC? Introducing a framework of early team planning in virtual teams. (Unpublished master thesis). Maastricht University, The Netherlands.

Moust, J., Bouhuijs, P., \& Schmidt, H. 2014. Introduction to problem-based learning: A guide for students. Noordhoff Uitgevers B.V.: Groningen, the Netherlands.

Salazar-Márquez, R. (2017). Digital immigrants in distance education. The International Review of Research in Open and Distributed Learning, 18(6). Retrieved from http://www.irrodl.org/index.php/irrodl/article/view/2967/4361

Toven-Lindsey, B., Rhoads, R. A., \& Berdan Lozano, J. (2015). Virtually unlimited classrooms: Pedagogical practices in massive open online courses. Internet and Higher Education, 24, 112. doi: 10.1016/j.iheduc.2014

Van Tilburg, J. (2014). Digital problem-based learning goes beyond the university itself. (Unpublished master thesis). Maastricht University, The Netherlands.

Veletsianos, G., \& Shepherdson, P. (2016). A systematic analysis and synthesis of the empirical MOOC literature published in 2013-2015. International Review of Research in Open and Distributed Learning, 17(2), 198-221. doi: dx.doi.org/10.19173/irrodl.v17i2.2448.

Verstegen, D., Fonteijn, H., Dolmans, D., De Rijdt, C., De Grave, W., \& Van Merriënboer, J. (in press). An exploration of Problem-Based Learning in a MOOC. In N. Dabbagh, M. Moallam, \& W. Hung, The Wiley handbook of problem-based learning. New Jersey, USA: John Wiley \& Sons.

Verstegen, D. M. L., de Jong, N., van Berlo, J., Camp, A., Könings, K. D., van Merriënboer, J. J. G., \& Donkers, J. (2016a). How e-learning can support PBL groups: A systematic literature review. In S. Bridges, L. K. Chan, \& C. Hmelo-Silver (Eds), Educational technologies in medical and health sciences education (pp. 9-35). Springer, Advances in Medical Education. Volume 5.

Verstegen, D., Spruijt, A., Dailey-Hebert. A., Clarebout, G., \& Fonteijn, H. (2016b). MOOCs and PBL: Project report. Maastricht University, the Netherlands. 
Wen, M., Yang, D., \& Rosé, C.P. (2015) Virtual teams in massive open online courses. In C. Conati, N. Heffernan, A. Mitrovic, \& M. Verdejo (Eds.), Artificial intelligence in education 2015 (pp. 820825). Lecture Notes in Computer Science, volume 9112. Springer, Cham.

Woods, D. R., Duncan-Hewitt, W. C., Hall, F. L., Eyles, C. H., \& Hrymak, A. N. (1996). Tutored versus tutorless groups in problem-based learning. American Journal of Pharmaceutical Education, $60(3), 231-238$.

Athabasca

University

(c) (1) 